Western University

Scholarship@Western

Education Publications

Education Faculty

2011

\title{
The I Teach Mathematics Online Project: Learning and Teaching through Innovative Practices
}

Immaculate Kizito Namukasa

The University of Western Ontario, inamukas@uwo.ca

George Gadanidis

The University of Western Ontario

Follow this and additional works at: https://ir.lib.uwo.ca/edupub

Part of the Education Commons

Citation of this paper:

Namukasa, I. K.,\& Gadanidis, G. (2011). The I Teach Mathematics online project: Learning and teaching through problem solving studied in video interviews on innovative practices. International Journal of Information and Education Technology, 1(4), 321-330. 
The I Teach Mathematics Online Project: Learning and Teaching through Innovative Practices

Immaculate K. Namukasa and George Gadanidis.

\begin{abstract}
Providing professional development and support resources that offer additional learning to what teachers might have studied at school, university, and in practice is an increasingly recognized way to support teachers Web-based resources promise to deliver content and pedagogical knowledge in ways enriched by digital technologies. We report on a prototype of a project, I Teach Math project, ITM, developed to deliver pedagogical content knowledge for teaching through problem-solving. ITM was designed from video interviews of selected mathematics teachers on their favorite lessons. On the ITM online database the videos are presented in short clips. Virtual learning objects are used to annotate and illustrate the content. The online environment was harnessed to aid teachers to observe exemplary teaching practices, to build a database of exemplary teaching, and for sharing ideas on teaching practices. In the process of designing ITM we surveyed existing online projects to select 10 major players for a comparative analysis. This paper reports on the development of ITM. It explores the digital-technologies utilized, the pedagogical content knowledge and pedagogical thinking shared by the teachers.
\end{abstract}

Index Terms - Professional development, I teach mathematics project, problem solving, content, digital technologies, virtual manipulative materials, pedagogical knowledge. 


\section{INTRODUCTION}

There is a trend in teacher education on researching the nature of mathematics required for teaching [1], [2], and a recent focus on problem solving as a pedagogical practice [3], [5]. Our research responds to the needs identified in the teacher education and problem solving literature: more sites where content knowledge for teaching is taught [6] to inservice teachers [3], connecting problem solving practices to problem solving lessons taught by teachers [3].

Online and virtual learning is increasing and it is facilitating delivery across boundaries. The computer and internet take-up in schools at 5.8 students to one internet connected computer in Ontario schools, in Canada, is higher than in households and private sector industries [7], [8]. Several of these computers are connected to intranet or internet [8]. A percentage higher than $82.5 \%$ of Ontario schools do have either board- or school-based intranet. "For schools, a broadband connection enables greater use of multi-media education applications by integrating images, text, data and sound" [8], p.15. The current technology trend in many schools is that internet is increasingly adapted as a medium of training. "Nearly 150,000 Grade 7 to 10 math students now have access to live, interactive online math help through the expansion of a pilot project funded by the Ministry of Education and Training, Ontario" [9]. 95.2\% of the schools already have access to education drill and practice software and websites. "The belief that the educational use of computers and the internet may provide an enriched learning environment for students, as well as a useful pedagogical resource for teachers is generally widespread" [8]. Teachers are increasingly sharing resources, mainly lesson plans, and collaborating through social networks. There is more to the internet than sharing lesson plans. Despite impressive infrastructure, there is room for improvements in updating learning software and increasing use of ICT in Canada and elsewhere [8]. 


\section{RELATED LITERATURE}

\section{A. Review Stage}

There is growing need for well-researched, practice-based and web-supported resources for teaching mathematics in novel ways. Elementary mathematics teachers need a support resource to be able to teach in ways that are encouraged by curriculum reforms. Research evidence shows that many elementary school teachers have never experienced modes of teaching that are encouraged by curriculum reform either as student-participants or as teacherobservers [10], [11]. For teaching through problem solving, which is encouraged in Ontario and elsewhere, many teachers may think problems solving is about word problems that are assigned at the end of a unit for students to apply their knowledge [12]. Yet curricula reforms are promoting problem solving as a central mathematics process [13], [14], [15] and novel pedagogy.

Existing resources that outline rich math problems are scattered in journals, curriculum documents and in the few available problem solving books. Descriptions of problem solving in approved textbooks and teacher resources have often been reduced to routine problems, to direct step-by-step guides to solutions and to problem solving methods [16]. Yet curricula reforms are promoting problem solving as a central mathematics process and pedagogical tool that promises to improve the quality, accessibility and relevance of mathematics learning. Reference [17] reviews literature on characteristics, design aspects and selection or generation of rich problems. The characteristics include the non-routine nature of the problems, the potential for insight, the interesting mathematics that the problems generate, the rich contexts utilize by the problems, as well as the mathematics modeling processes involved. The problems may have more than one solution strategy, and generate insights as they open the way to new 
territory for further exploration. These problems can challenge and enliven the study of mathematics, thus making mathematics more interesting to students. Problem solving is also a skill needed in adult life. Many educators see the use of problem solving in teaching to be a way of making mathematics more meaningful for today`s students.

Recently in North America the focus has shifted from problem-solving as one of several classroom activities to teaching through problem solving [18]. No wonder, recent research on problem solving involves problem solving not only as learning approach but also as a pedagogical practice [4], [5]. Reference [3] assert that research is needed that connects problem solving research to problem solving lessons taught by teachers. Elementary mathematics teachers need support resources to be able to teach in ways that are currently encouraged by curriculum reforms in several countries. Teachers would benefit from viewing innovative mathematics teaching: for teachers who are implementing related reform teaching strategies such resources offer ground for reflection on their own practice. Thus, inspiring more innovative practices and correcting misconceptions about reform practices [19].

Teaching through problem solving is a more complex task and the pedagogical content knowledge involved appears to be complex. Online resources are emerging to mitigate the limitations of the print medium. Indeed the online environment does offer an avenue to observe innovative and successful examples, a place to download and listen to video casts and a forum for discussion and sharing teaching ideas as well as a space to share examples that incorporate new technologies in teaching through problem solving. 


\section{METHODOLOGY}

\section{A. Interpretive Inquiry}

We consider the problem of understanding and disseminating pedagogical content knowledge, particularly its interactions with classroom practices to be an interpretive problem not unlike attempts to cautiously understand historical texts hermeneutically. Hermeneutic research involves re-looking to find alternate ways of interpreting a phenomenon [20], [21]. Through studying interviews with teachers on exemplary lessons, we seek alternate ways in which the phenomenon of pedagogical content knowledge can be studied and interpreted.

\section{B. Review of existing web-based projects}

We surveyed existing online projects to select 10 major players for a comparative analysis. We selected projects that we and our teacher and educator colleagues use in teaching.

\section{I Teach Math Development}

The development of the I Teach Mathematics project involved interviewing selected mathematics teachers on their favorite problems solving lessons. The teachers were identified from our related research and teaching projects. Interviews were video recorded. We asked teachers the several interview questions, including: What would be one of your favorite rich math classroom activities? Why is it your favorite? How is it mathematically rich? How do you know whether the activity is successful?

\section{Video Data Editing and Analysis}

Construction of the web pages and data analysis involved watching the videos several times. Video recordings were analyzed using video data analysis [22], [23]. We identified several teaching moments around which we created the video clips. Clips were then illustrated, 
linked to relevant websites and documents and enhanced by professionally designed virtual manipulative and learning objects. Video clips at the website were also transcribed and interpretively analyzed.

\section{A SAMPLE OF EXISTING WEB-BASED PROJECTS}

The existing web-based mathematics teaching major players in North America focus on a scattered range of issues including mathematics activities, puzzles, interactive tools and lesson plans but only a few of these focus on pedagogy involved in teaching in novel ways. Apart from the focus on interactive manipulative materials, most of the existing players focus on web forms of traditional concrete and print resources. Out of the ten major players surveyed, three provide alternative e-technologies on problem solving. Below is comparative analysis.

One alternate technology most commonly accessed in our pre-service teaching is the National Council of Teachers of Mathematics (NCTM) illuminations. This resource offers a wide range of free lesson activities. It integrates traditional worksheets and java applets and incorporates voice.

A second alternate technology is National Library of Virtual Manipulatives (NLVM) by Utah State University. NLVM offers free virtual manipulatives and sells CD versions of its online resources. It integrates worksheets and java applets.

Mathematics Forum by Drexel University is the third alternative. It offers free math help, problems and resources. It sells print resources and problems of the week. It integrates worksheets and a discussion board.

Fourth, Center for Education in Mathematics and Computing (CEMC) at the University 
of Waterloo provides free and commercial online math resource (e.g., fun resources and games at Math Frog) for parents, teachers and students. It integrates java applets.

Fifth, Literacy and Numeracy Secretariat, Ontario Ministry of Education (LNS) offers free web casts and video archives addressing broad topics including, coaching for student success in mathematics. It integrates video tutorials and classroom examples.

Sixth, Ontario Ministry of Education provides e-Workshops that integrate video demonstrations and addresses problem solving among many other topics.

Seventh, Understanding Mathematics by Neufeld Learning, NL, Systems is an example of an entirely commercial alternate technology that focuses on teaching concepts by using interactive materials. NL integrates applets and voice.

Eighth, CASMI, Communauté d'apprentissages scientifiques et mathématiques interactifs is an example of a database of problems and solutions that has a discussion forum and virtual community of problem solvers.

Ninth, Teachers Connecting, is an example of a virtual community of teachers. This web resource is described as a place for K-12 teachers to find other teachers for cross-classroom collaboration.

Lastly, Gizmos Resource Catalog, is yet another -the tenth- player. It is described as online simulations that empower inquiry and understanding. It offers interactive objects for teaching mathematics and science concepts for Grades 3 to college.

The comparative analysis of the existing resources, therefore, identified several areas in need of improvements. Several existing online based materials could be enriched by multimodal presentations such as video and electronic learning objects. The integration of video casts was unique to 2 of the 10 technologies that we reviewed. All of them offered some form 
of downloadable text based resources especially electronic copies of worksheets and lesson plans. Tools such as interactive manipulative material for both teachers and students are rare. There is potential in exploring the role of digital learning - especially resources with annotated, exemplary tasks, interactive manipulative materials, discussion boards, streaming video and screen casts - in sharing best practices, teacher knowledge and resources. Only one of the alternate technologies - CASMI - gave teachers the opportunity to create, annotate and add mathematics problems to a database. Also absent was a resource showing synergy among design, research and practice. None of the online problem solving resources reviewed focused on issues of design and selection of tasks as well as the skills, knowledge and pedagogy that teachers use in teaching through problem solving. Thus when developing I Teach Math, ITM it was important to focus on building a resource that focuses on specific reform teaching strategies, particularly disseminating the pedagogical content knowledge involved in such teaching. I Teach Math: A prototype in development.

\section{I TEACH MATH: A PROTOTYPE IN DEVELOPMENT}

I Teach Math, ITM, is an online resource designed to support K-8 teachers with skills, innovations and resources for teaching mathematics in to support teachers who seek to teach in novel ways. It harnesses learning technologies specifically video casts, virtual manipulatives and simulations to deliver complex content and pedagogical knowledge and begins with knowledge of teaching through problem solving. The prototype was developed by the co-authors in response to the growing need and interest in web-based resources. Interactive content and multimodal communication of ITM is ideal for sharing resources and the pedagogy involved in innovative and successful lessons. The authors brought to ITM their 
teaching and research experience with students, preservice teachers and inservice teachers. The ITM project emerged from their ongoing research on mathematics interactive manipulative materials, rich mathematics problems and mathematics-for-teaching in which we study mathematical activities that influences classroom practice. ITM web-resource is organized around several successful classroom tasks and video recorded interviews of selected mathematics teachers on their favorite innovative lessons. The videos were presented in short clips, annotated by visuals and virtual learning objects and linked to relevant documents and sites. Each task is designed on an interactive page. In the interviews, teachers talk about task design, selection, implementation and assessment. The interactive pages offer much more. The tasks were implemented and assessed in classrooms by experienced teacher. Worksheet, lesson plans, and other supportive materials, which were shared by the teachers, are attached. Professionally designed mathematics manipulative materials that simulate the mathematics concepts involved accompany the clips. Teachers may use the worksheets and presentations slides when they wish to replicate the lessons.

\section{A. Objectives of I Teach Math}

The following are the objectives of the ITM:

1) To create, develop, and test innovative ways of teaching mathematics integrated with new e-technology capabilities and existing processes so as to improve the quality of teaching mathematics through educationally sound and research based practices in schools.

2) To offer K-8 teachers access to a well-researched, practice-based and digital-technology supported resource with annotated exemplars.

3) To provide skills and support resources to Elementary mathematics teachers to enable 
them to teach in ways that are encouraged by local, regional, and international curriculum reforms.

The prototype built involved working with three selected teachers to design four online interactive activities. Screen captures of sample images are provided in Figures 1 to 4. Electronic web pages are temporarily found at: http://publish.edu.uwo.ca/george.gadanidis/Michelle1 (see page capture in Fig.1), http://publish.edu.uwo.ca/george.gadanidis/Michelle2 (see Fig. 2), http://publish.edu.uwo.ca/george.gadanidis/Sarina (see Fig. 3), http://publish.edu.uwo.ca/george.gadanidis/wiff (see Fig. 4).

\section{PEDAGOGICAL KNOWLEDGE AND THINKING}

In this section we present excerpts of the pedagogical knowledge shared by the teachers showcased in ITM. We want the words of the teachers to speak for themselves on matters of lesson design, implementation and assessment, and to give the reader a first-hand sense of the nature of their pedagogical knowledge and thinking. As we listened to the interviews and read the transcripts we were left with two important ideas. First, what these teachers chose to share as their successful lessons involve pedagogical strategies that can be characterized as "learning through problem solving." Second, the teachers' comments and reflections about their teaching practice help us see that their pedagogy is also developed by "improving their teaching through pedagogical problem solving." That is, what these teachers share are not final solutions to what makes innovative mathematics teaching but rather a work in progress. What the teacher shares is their pedagogical knowledge and thinking as it is evoked in practice. It is a pedagogical problem whose solution they continue to refine. This parallel between learning mathematics 
through problem solving and learning to improve teaching through problem solving was an unexpected connection when we started this project. Also the manifestation of teacher's pedagogical knowledge and thinking that is evoked in practice was an unexpected result of the inquiry. The connection between learning and improving practice through problem solving as well as the window into teachers' pedagogical thinking gives us hope about the future life and impact of the ITM.

\section{A. The Math of Chop sticks}

In this page (captured in Fig. 1) Ms. Cordy shares a Grade 2 and Grade 3 combined, Grade2/3, class task that we refer to as the Math of chop sticks. She sets the task in the context of dining at an Asian restaurant: "Our class is going to the Mandarin [restaurant]... how many chopsticks they would need?" Her lesson's goal was to use the solutions that students came up with as a basis for introducing the concept of unitizing and varied approaches in multiplication. The page is organized around seven video clips described below. Three clips are annotated by slides from the Smart Board presentation that the teacher used. One clip is annotated by a dynamic visual of $\mathrm{n}$ array shown after a visual of repeated groups to relate repeated addition to grid multiplication.

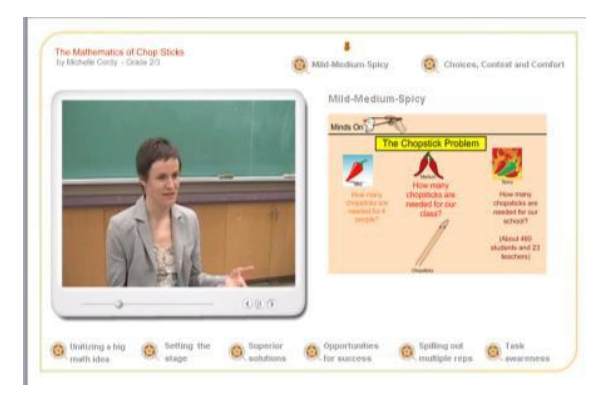

Fig. 1. The mathematics of chopsticks by ms. cordy. 
1) Mild-medium-spicy: This is an introductory clip in which Ms. Cordy shares her new strategy of posing mathematical problems and giving three options: the mild, medium and spicy respectively: A family of four goes to a Chinese restaurant, or our class [of 20] is going to the Mandarin, or our school [of 600] is going to a fabulous excursion. How many chopsticks would they need?

2) Choices, context and comfort: in this second clip the teacher comments about her rationale for selecting this task as one of her favorites: one, "the context was a real world context ...the students could imagine themselves" in the situation; two, "the kids each had an option of where to go" with solving the problem;" and three, "kids made choices depending on their level of comfort." These first two clips are about the design of the task. The task includes a common context and the problem is designed with three versions so as to motivate learners of varied backgrounds.

3) Unitizing a big mathematics idea: In this clip on the implementation of the lesson, the teacher explains two key concepts involved in the chop sticks task-unitizing, counting by twos and different ways of multiplying. These two concepts were the basis of the unit. She found the activity rich in the following ways:

I was introducing multiplication. By having the chopstick problem, it gave me an opportunity to talk about unitizing, so we could talk about two chopsticks individually ... and [also] by attaching them and also counting the groups [of two attached chopsticks] ... (that is a difficult idea for primary children ... unitizing, counting a group of objects as a unit) .... Chopsticks are attached; so it is a beautiful example of unitizing. ... As children were solving the problem ... it allowed for so many different types of representations. Kids could do repeated addition, they could double it ... they could diagram and then count ... they could 
count by twos. So afterwards we were able to share all the [three versions] chopstick problems and what emerged were all the different representations of multiplication. And then from that we could talk about arrays ... and make that the point of departure.

4) Setting the Stage: This clip has a link to the teachers' Smart Board presentation. In the clip the teacher discusses the presentation strategies used, including; the Smart Board media used. She also talks about the place in the sequence of the unit where the task fits_-"at beginning of the unit on multiplication;" and the directions that the subsequent lessons took- "refining those different approaches of multiplying that had naturally emerged."

5) Superior Solutions: In this clip the teacher reflects on the assessment aspect of the activity and a question that she says,

"She wrestled with ... of whether there is an approach to multiplication that is superior to the others.... If the child gets the right answer is the solution of counting by ones less valid ... than that of counting by two?" The teacher resolved the question for herself by considering that it would be different for her assessment at the beginning of the unit and the assessment at the end of the unit: "When we did the activity at the end of the unit I wanted to see multiple representations of multiplication."

6) Opportunities for Success: This clip is about the criteria used by the teacher to judge successful tasks:

"How the kids are engaged in the task? Is it doable? Do they know where to start? Will they have some success? ... In both [the pre and post unit task] everybody had success; providing an activity where everyone can be successful" is a key determinant of the success of a problem solving task. 
7) Spilling out multiple representations: in this seventh clip the teacher highlights that "it is nice when the knowledge comes out of the question/problem. An array representation for grade twos that came from the students." The teacher begins to comments on the students' learning that took place.

8) Task Awareness:

I would do the problem again but now I am aware of the short comings ... what made the spicy difficult is that ... if children were able to see that basically we were doubling here then they chose the spicy. And they really did not have far to go ... they were basically doing computation, it was more trying to add the three digit numbers that was problematic for them not so much the multiplying. So the problem with the spicy option is that they went into three digit additions not so much the multiplication [by two]. That is the short coming of the problem. I would do the problem again but now aware of the shortcomings.

This clip illustrates a teacher reflecting on the shortcomings of the tasks for purposes of improving her practice.

\section{B. The Great Fraction Debate}

On this page (shown in Fig. 2) Ms. Cordy shares abouther practice, which she adopted from her social studies teaching, of using debates for teaching mathematics. She names the activity, the Great Fraction Debate. The page is organized around six video clips. One clip is annotated by a visual of a fraction learning carpet. There is also a link to the teachers' Smart Board presentation on the fifth clip. The last clip is illustrated by a dynamic visual of a pizza with two pieces being layered on a whole pizza to illustrate a mixed number. 


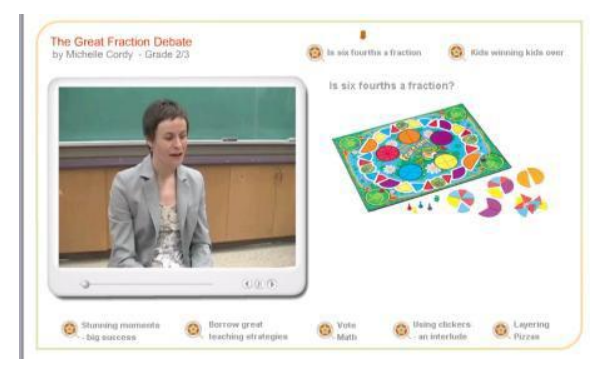

Fig. 2. The great fraction debate by ms. Cordy

1) Is sixth-fourths a fraction? Here the teacher introduces the innovative learning strategy of using a debate. She talks about how she corrected several students' misconceptions about fraction combining. She further shares how quickly her students got engaged in the activity: Well ... I tried to do something that I had not done before ... to have a mathematics debate. I thought it would be fun to stress the part wholeness of fractions by having a debate of whether six-fourth was a fraction. So I presented my Grade 2 and 3-the 7, 8, 9 years old children, with the fraction six over four and I said, 'is this a fraction? ' ... what is stressed in grade two and then grade three is ... the part-whole relationship. The numerator is the part and the denominator is the whole ... when we talk about fractions we talk about how many parts [of the whole] there are.

It was hilarious ... how engaged my students were [in debating whether six fourths is a fraction]. Right away no, [there is] no way that is a fraction, absolutely ... no. Some kids said, 'maybe'. And so with lots of manipulatives in my class - snap cubes, pattern blocks, tiles, and the learning carpet - the students took it to themselves to try ... to prove that it was absolutely not a fraction or to prove that it absolutely was. And as I went around from table to table from group to group, I just came back to the idea-what was the part and what was the whole. Because what a lot of the kids had said was that six-fourths can't possibly be a fraction, what they kept doing is changing the whole they would change the whole [how many parts 
there are in total] so instead of 4 pieces let's say they would add two more pieces and then go okay ... well ... this is six over six ... So as I went around I had reinforce ... the whole and the part.

2) Kids winning kids over: In this clip the teacher talks about how students explored the problem and the ways in which a debate encouraged students to communicate the mathematics involved in converting a fraction to a mixed number. It is a clip in which she shares students' experiences:

Finally one of my students said to her group 'it is like when we order pizza' and so they drew a box and inside they drew two pizzas. She drew the two pizzas, said, 'let us divide this into four, this is four pieces, it is a whole, four parts make a whole and then two more' and they could represent that. It is a bit of a risk that I took ... by having this debate, it just stimulates the kids to talk and think and try to prove and really engage in work that is very mathematical. Okay let us prove it, let us make conjectures and let us see where this goes. Through the pizza example ... one group was able to explain to the class what they thought and slowly they won kids over, they won kids over. Then the bell rang, it was funny, it is recess. We've been in this debate ... where did time go? It was kind of fun to get lost in an activity like that.

3) Stunning moments - big success: Ms. Cordy shares a teachable moment during the debate activity, her judgment of whether the activity was successful, some challenges involved, her focus on specific curriculum concepts as well as the mathematics concepts learned during the activity:

The activity was successful ... but for some kids.... One kid even said no ... basically figured out how to add fractions by adding the numerator without adding the denominator, 
which is a common mistake that students make. I am sitting there completely floored that a kid in Grade 2 is adding the numerator acknowledging ... that the denominator has to stay the same. That was an absolutely successful, stunning moment. So for that student, absolutely successful. For another student who described the pizza [example] to the class, a hugely successful moment for that child. The notion of what is the part, what is the whole was so heavily reinforced.... So for them at least the part-whole relationship was reinforced. But I am quite sure that not everyone grasped the overall concept. I think the important thing in my mind ... was that I wanted the students to understand.

4) Borrow great teaching strategies: In this fourth clip the teacher comments on her rationale for borrowing teaching strategies from other subjects:

I think sometimes to engage in mathematics as they engage in other subjects ... not being stuck in what ought to be mathematics instruction ... is useful. This side of the class is for the idea ... and that side is against it and they offer their arguments. So kind of borrowing that pedagogy and taking it for mathematics.... You have never seen 8 year olds so passionate about or so adamant that it [sixth-fourths] was not a fraction or that it was a fraction. And so bringing in that ...emotive part of it is really fun.

Vote math: This clip is illustrated by a slide showing how students might use pattern blocks to explain their thinking about whether six-fourths is a fraction. The teacher shares that she posed the question and the students had to vote on the Smart Board.

5) Using clickers - an interlude: This is an interlude clip in which the teacher shows how she uses clickers (a Smart Response system) in conjunction with the Smart Board in the class to poll students on knowledge and recall questions.

6) Layering Pizzas: Here the teacher emphasizes the strategy of using meaningful contexts in 
teaching, she shares an illustration of mixed numbers as layered fractions:

We can take an opportunity to think about ... what makes sense. With the pizza example, after the one student drew the picture of this is one of the pizzas four out of four, it is whole, and then we have a half of the pizza left - two out of four pieces left, and then another student is like sometimes we do not have enough room in the fridge so we layer them on each other. And that is sixth-fourth. Inside I am doing this happy dance. You have to stress part-whole but there has to be some context that makes sense for them.

\section{The mathematics of swinging pendulums.}

Ms. Sarina (shown in Fig. 3) shares a about a multi-period lesson on Pendulum mathematics with Grade 8/9 students. The lesson involves experimentation, collecting, graphing and interpreting linear data using dynamic geometry software. This first of eight clips is illustrated with a downloadable lesson worksheet. The second is linked to the lesson worksheet. The third clip is illustrated by an interactive simulation of a pendulum experiment, as well as a graph of the data and a link to plotting graph in Java Sketchpad - a www component of the software GSP. A link to the curriculum guide for grade 9 and 11 is provided with the clip entitled expectations neatly covered. The New? Wanna Try It? clip shows an overview of the experiments for teachers who may wish to replicate it in their classrooms. Ms. Sarina similarly shares not only information on the design, implementation and assessment of the task but also her pedagogical strategies.

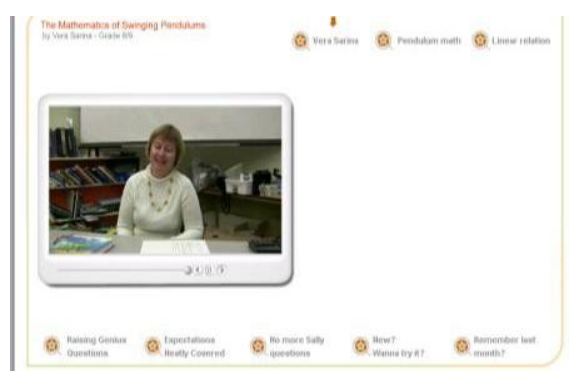

Fig. 3. The mathematics of pendulums by ms. sarina. 
1) Pendulum Math: In the first clip the teacher introduces herself and the school and grade where she teaches. In this second clip the teacher introduces the activity. The activity is about:

How to connect data to the visual representation or the data to the graphs. The activity was a combination of hands on investigation then computer analysis then whole group discussion on results. So the whole idea was to collect data on the time that it takes the pendulum to swing 5 times and the length of the string. They start with a string about $30 \mathrm{~cm}$ long, they attach it ... to the table with tape, swing it 5 times with a stopwatch to measure the time, they do $40 \mathrm{~cm}, 50$ and so on. They collect the data in the table... after that they proceed to the computer lab. They use Geometer Sketch Pad, GSP Software - they plotted the data, drew the line of best fit ... and found the equation of the line using GSP's graphing function. .... It was a preliminary of how their ideas [on the equation, the meaning of coefficient of $x$, the meaning of the constant term in the equation of the line, the $y$-intercept in terms of the line and the real data] ... They answered those questions, they sent their work to me [by email] ... I marked them and sent back the responses.

2) Linear relations: In the clip she further shares about the third part of the activity that involved discussing the results:

Next class when they came to my room I projected one of their work on the big screen and we started to analyze what they discovered. For instance, one of the questions was why the points in the data that they collected did not form exactly a linear relation so that they had to form a line of best fit, to show the relation .... We discovered that the more accurate the data was of those points the more close to the line of best fit.... [We did a] bit of play on the big screen... we looked at different lines of best fit ... and we saw how if it is a different 
number [the constant + coefficient in equation, $y=a x+b$ ] in the equation, how the line starts to change." ... It was a good wrap up in terms of finding the connection between the real life investigation and the mathematical model which is always precise linear relation such as $y=$ $2 x+4$

3) Raising genius questions: This clip is in response to the question, Why is the activity your favorite? The teacher shares her criteria of a rich activity, and the students experiences with the activity:

This activity ... it answers my criteria of a good activity in the classroom. First, through this activity they [the students] discovered on their own a mathematical concept ... through solving this problem ... the first time they used a line of best fit and they fully understood that the line of best fit - which they find a very abstract notion, for them ... we use a line of best fit because there is a tendency, maybe our data is a little bit ... sloppy ...they got the line of best fit very nicely.

Second, the first time they encountered slope and y-intercept. ... the question was raised ... what are these numbers in the equation [of the line]? ... So the main focal point of analytical geometry - visual ... representation of the relation ... different representations of the relation - [making connections among the] line, graph, equation, real data, that basically is very hard to build that in their minds ... They saw it. ... the first step ... then we will dip into it during regular lessons when I explain ... Some of them got it... [in terms of] the real situation ... Some of them even got it from the line, like that is how we changed [it through a]... A third criteria of a good activity is that when it poses the questions that will be answered later by me. They come in your classroom ... they are good kids ... but it is like is why she telling us this stuff, we did not have questions about it. ... But here it is a nice thing: And I say, now remember 
... remember the question I asked you what the coefficient of $x$ meant in the data and on the line ... now let us ... explore where this comes from. Then you have their attention. Because they leave this activity with questions and this is a better thing ... They will hypothesize, and they will form this curious question mark: What is this?

4) Expectations Neatly covered: In this clip the teacher shares about the concepts explored in the lesson: First of all, the concepts ... that we covered nicely and neatly are: collecting the data, graphing the data, line of best, finding the equations, [and] talking about what is linear what is not linear. So all are basically the expectations in the relationship unit. These concepts were nicely covered.

5) No more Sally questions: In this clip the teacher contrasts the task to the traditional textbook questions:

"It is one thing to open the book and the book says.. It is another thing to collect the data. Find the relationship on your own."

6) New? Wanna try it? In this clip she shares about the experience of two teacher colleagues who replicated the task.

We have two new math teachers in our schools this year ... we had a little meeting where I showed them the textbook, gave them the computer assignment, taught them GSP, gave them the follow up question, then they did it.... Absolutely it is very replicable. ... In the textbook they do not include the computer component and they do not have the follow up questions. What I added as well was the discussion afterwards ... The technology aspect of it ... is unbelievably great.

We did it in 3 periods. First period was to collect the data. Second period was to do the computer part of it.... And the third class was the ... the class discussion, which I did not mark 
of course, but it gave them the ... understanding of what they did, how it went and to pose more questions towards the next steps.

7) Remember last month? The teacher shares how she assesses students learning and her teaching of the activity.

You feel it. If they are lost during the activity, they keep asking questions ... Oh you see it right away. Like if the results, you predict what they will discover .... And if the results are different ... the results of the activity is not the knowledge that you want them uncover ... there is something that you missed ... Grade 9 kids ... if they like it ... if they feel they can do it, good for you. Also if later on ... if they do remember it in a month. I know it is not that every activity goes right the first time. Then you either discard ... or you just adjust it for next year.

There are so many expectations in the curriculum ... So with a good activity you have to cover a lot... you have to cover more than one ... because you spent 2, 3 classes. In this activity I spent 2 and half classes. So I have to cover [several] expectations ... So pack it in ... expectations of the Relationships unit, you can pack it in. ... It is completely doable if you can plan your activities with a vision of covering the expectations.

D. The Mathematics of Wage Labor

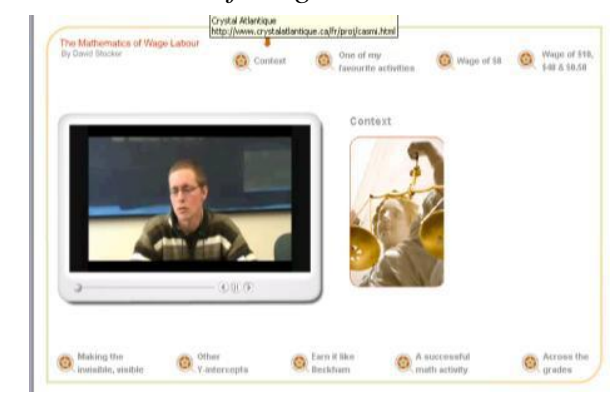

Fig. 4. The mathematics of wage labor by mr. stocker.

In the mathematics of Wage labor, Mr. Stocker (see Fig. 4) is interviewed about a Grade $7 / 8$ lesson that links mathematics to social justice. The lesson centered on variations in wages 
and graphical relationships among different wages. Several visuals, including a visual of a graph, are used to illustrate the nine clips. An interactive graph with which a viewer may select to plot selected wages and study the relations accompanies the fourth clip entitled, Wage of $\$ 10,40$ and 0.50 . The clip on Other Y-intercepts includes a comparison between two graphs \$ 200 cash and \$ 6 per hour against that of \$8 per hour. Mr. Stocker also shares details on the lesson as well as his pedagogical knowledge and thinking.

1) Context: In this clip the teacher, Mr. David Stocker, describes a problem about teaching mathematics. The activity he selects to share seeks to address the problem by setting mathematics within a social justice context.

The fortress of irrelevance of the mathematics class room, is what I call it; that is, because ... where students are constantly asking? 'so what' Why would I ever need to know this math? ... When would I ever use it in my life? .... And so over the course of 8 years I wrote a book called Math That Matters that takes those immediate social justice issues that they live every day of their lives and links them to the math in a way that is not an add on. ... It really is meant to enhance both of them [math and social justice], greatly; by engaging them [the students] far more in the classroom discussion.

2) One of my favorite activities:

One of my favorite activities is around bringing algebra into the talk of minimum wage, wage labor in general. It fell through a unit ... and within that unit that began with brain storming, well, what do you know about minimum wage? ... We filled two entire walls with questions from Grade 7 and Grade 8 [students]. And then we built the mathematical activities around some of the questions that they were interested in. One of them [the questions] was to do with understanding what the NDP party [a political party in Canada] was trying to do 
moving the minimum from about 8 dollars 50 cents roughly, moving it to 10 dollars an hour. In this second clip he describes the activity that was intended for three weeks but in the teacher's words "ballooned into three months ... as it just got more and more complicated and mathematical and the students were engaged in it."

3) Wages of 8: In this clip the teacher described the implementation of the first part of the multi-week activity.

We took the whole class out onto to the field with two really large ropes and made an $x$ and $y$-axis right in the middle of the soccer filled. Okay, let us see if you graph algebraically the relationship between this two variables - the number of hours you work on the $x$-axis and the amount that you are paid on the y-axis. A student jumps onto the grid and says, 'okay well I have worked an hour and I have made about ... 8 dollars an hour. ' Okay well maybe 5 people would show the line, where would you stand after 2 hours, after for 3 hours, after 4 hours and after 5 hours of work? ... And immediately you see people more engaged just because they are doing it physically..... And we go from there and we say, 'do you agree with where they are placed, do you want to make modifications. And why? Can you justify?

4) Wage of $\$ 10,40$ and 0.50 : In this clip the teacher describes the second part of the activity in which more lines are graphed and comparisons are made among different wages. He also shares an assignment that followed the class.

And then keeping those people in their places showing that line [of wages $\$ 8.50$ ] we ask questions: What would a $\$ 10$ an hour look like for the first 5 hour? ... And then they start to make comparisons .... And then we ask questions so, 'why the NDP, do you think they trying, why are they doing that.... Does that [moving the minimum wage from 8.50 to 10 dollars] look 
like a significant difference in wages? ... And then we need to build more of the contexts. So we follow sort of the interests of the students.

Some students say well, David what do you make? So I say roughly after working 8 or 10 years with the board let us say roughly $\$ 40$ an hour. So another 5 students jump on the graph and show the line for 40 dollars an hour line. Someone says wow that is significantly different. I am noticing that line is a lot steeper. So the language starts to come out of the group when we are talking about the slope ...just quite naturally.

One of the assignments was for the students to go home and look at their clothes. They were given 20 stickers ... to write down where their clothes came from.... So the Grade 7s and $8 \mathrm{~s}$ both did that and they came ... we had a big Mercator's projection map on the wall ...Okay well let us put up [stickers for] where your clothes are from. That is about 60 students, 20 stickers each; you got a lot of stickers. A pattern clearly emerges where the whole of South East Asia is completely covered: ... There are very few [clothes] from North America. And people say well, why is that? ...because ... "So we say okay, well, ... let us do an investigation of how much people in these countries that are working in these garment industry are making... Students can do this research... The bigger picture is this circle oflow wage labor, a much bigger circle that does not get the same political attention ... So we return to the field and have them recreate the lines that they have already done before. And we have them put the first 5 hours of someone working for 50 cents an hour, who is making their clothes. Again the stark difference ... is enough to make people... say, 'well after five hours they are ... are just over a quarter of the way to the minimum wage earners first hour ... and you hear them talk about those reference points .... And the emotional attachments starting to come out. 
In this clip we see the teacher beginning to share students' learning experiences.

5) Making the invisible, visible: In this clip the teacher shares about how the questions and what students learn from the activity become more complex. He shares his passion on the role of mathematics at making the visible invisible and at crashing the myths around power and oppression.

The other thing that starts to come out: ... that somehow we can use math to make justice visible in a way that it has never been made visible. And also to show people that they have a direct relationship with people in different corners of the planet that is a relationship of power, privilege and oppression. That is always invisible. And then people begin to ask more complicated questions. That is not fair David because if you live and work as a minimum wage earner in Ontario, oh sure you are getting more money but it costs more.... When you are working in the garment industry in Indonesia you make less but your cost of living is less. Well okay fine, let us look into that.

Why don't we create a purchasing power comparison so what we research how much it costs to buy things in Ontario that you may also be buying in China... We make the list as broad as we can with many items as we can and then ... with the internet... to find how much things cost...And the students can create a ratio of the purchasing power by saying okay at the end of the day a minimum wage earner in Ontario can purchase 80 bus tickets whereas a worker in China can purchase 10 bus tickets. So is a ratio of 80 to 10 , or 8 to 1 . That is one ratio. And then we go through those many items as we can to create those ratios that then we average ... to add to our accuracy ... And so then the ratio ... is about a purchasing power ... you can go back out and re-graph that ratio and essentially show that the difference in the lines changes very minimally. And so this is what I call, using mathematics to crash the 
myths... around power and oppressions ... using ... math.

6) Other Y-intercept: This clip is about modifying the wages considered to include lines whose $y$-intercept are above or below zero ... points where lines intercept, and generally increasing the complexity of the mathematical skills involved.

I mean lines $y=m x+b$, the $\mathrm{y}$ intercept is zero but there is nothing to stop you from going into $y$-intercepts that are above or below zero.

He develops with students a context for the line $y=m x+200$. Then you can ask questions like well at what point do those lines intercept. Is it really to your advantage to take the 200 upfront, how many hours until you are disadvantaged by that relationship?

So making two lines equivalent at what point? That is a very difficulty skill and they can figure it out in many different ways. They can figure it out physically... they can say ... well, let us extend our space here and go beyond five hours and see where we cross ... or students might try guess and check or they might try any number of strategies ... and you know sometimes you are adding in the language: So talk to me about the slope as we continue this way, so talk to me about what the y-intercept of 200 means in the real world.

In response to the question, "Can you start below the line?" the teacher uses another context for the graph $7.50 \mathrm{x}-145$.

7) Earn it like Beckham:

Sometimes of these [comparisons] are very humorous if not very sad ... We say okay who are your favorite stars or your favorite pop singers, your favorite sports figures. And then we talk about David Beckham... the famous soccer play ... [who earns in total of about] 45 million dollars [a year]. And they [the students] can work out mathematically how much is that 
hours that Beckham earns ... [then] make a comparison between a minimum wage earner in Ontario and Beckham: Are they both working 40 hours a week? Is that fair? ... So when they work it out mathematically they find that Beckham earns roughly 24, 000 dollars an hour. People are just blown away by how much money that is. So we just go back out to the field. ... If Beckham earns 24, 000 dollars in his first hour then where is his first point. And you figure that out based on 1 meter off the $\mathrm{x}$ - axis is roughly [24000/8] 3 kilometers [that is, $3000 \mathrm{~m}$ ] from the x-axis. And so you can take a group of students and adults ... and say I need you to take this mathematical meter clicker and I want you to go $3 \mathrm{~km}$ and see where that first point is for Beckham, and we will see you at lunch.

And I return again ... so tell me about slope. And someone says for me when I look at these lines I think about tobogganing ... And when I look at the line of a worker who is making my clothes, if I got up that hill with a toboggan and I came down that hill I would be really bored. Because it is not much of a slope. And as I move up to the 8 dollar an hour line, the slope is not too bad. And then the 10 dollars line. I am not sure I could tell the difference between those two slopes. As I move up to the teacher's salary I am starting to get a little scared because I am going down the hill quite fast. But if I move onto the Beckham line that is what I call, 'a sudden death slope'. And people burst out laughing because they understand at that level what that line means as this student has connected it to his or her love of tobogganing. So there is this emotional engagement, there is this deepening complexity of the mathematical skills and it is all embedded in a context that has deep relevance to their coming lives as wage earners.

8) A successful math: In this clip the teacher shares his criteria of a successful problem solving tasks. 
What makes a mathematics activity successful...You see that there is emotional engagement, that kids care, that there is some sort of a range of emotions, there might be anger, there might be feelings of quilt or sadness ... there might be humor, but there is an emotional engagement in the lesson... There has to be a real reason to be using the math. So it cannot really be a tack on ... entirely without the math. The math has to add to a greater understanding, more complex understanding of the topic. There is the kinesthetic component ... al lot of math activities stay too close to the mathematics intelligence and, may be, the linguistic intelligence, but as soon as you move out into the kinesthetic realm I think you engage a lot, a lot more of the students... I am looking for the opportunity to get out and move with your body because when you do things with your body it is much harder to forget. I am also looking for ways that I can evaluate effectively to tell whether or not to ... we have caught all the students or a selection of the students. And most importantly for me particularly at City View High school [an small size, alternative public school with a focus on social justice issues] ... there has to be a real social context for the mathematics activities ... it has to matter to the students' lives, in a way that talks about power, and privilege and oppression because every single person in my classroom is a part of those relationships.

9) Across the grades: In this clip the teacher shares about the ways in which the activity may be modified for earlier or later grades than Grades 7 and 8, as well as the rationale for engaging students in mathematics contexts that have to do with power and justice. 


\section{LEARNING AND IMPROVING MATHEMATIC TEACHING}

We have presented a bigger part of the transcripts of what teachers shared in the I Teach Math Project. In all four cases, teachers describe the activities and talk about task design, implementation and assessment aspects. Of the criteria of innovative and successful lessons, the teachers identify: the ability to evoke emotional engagement, to orient attention, for students to make sense of the mathematics involved and to explore more complicated mathematics, and the potential to lead to explorations of mathematics content outlined in the curriculum. Looked at from the lens of task design, the activities shared are not routine exercises, they utilize rich, real life contexts, they generate interesting mathematics ideas -several of which are specified in the curriculum for the grades and each one of them involves more activity, discussions and investigations. The activities vary in grade levels and time length. Ms. Cordy shares single lesson activities, Ms. Sarina's activity took close to three lessons and Mr. Stocker's activity spanned weeks.

But there is more: The teachers also share reasons for selecting the particular activities as their favorite; they talk about the students learning experiences; and reflect on their teaching strategies. Among the pedagogical strategies that teachers reflect on are: borrowing instructional strategies from other subjects, circulating around the room during problem solving lessons, selecting and revising textbook problems to make them elicit more complex conversation, using problems that cover more than one lesson and several expectations, and reflecting on the lesson to judge appropriateness and success. Several pedagogical knowledge, thinking and practices shared in the excerpts can be characterized as learning through problem solving and improving teaching through solving pedagogical problems. Rather than discussing in detail issues to do with task design, lesson structure and nature of mathematics 
involved, we elaborate on these two important ideas of "through problem solving."

\section{A. Learning through Problem Solving}

During the math of chopsticks activity Ms. Cordy reports that her grade $2 / 3$ students learned several mathematics concepts. We were "able to share all the [three] chopstick problems and what emerged were all the different representations of multiplication." The teacher further comments that, "it is nice when the knowledge comes out of the question or problem." She further makes reference to her intent in relation to the curriculum guidelines "I wanted the students to understand ... I wanted to make sure that I was still in the curriculum guidelines." For the debate lesson, she shares about a stunning moment, "With the pizza example after the one student drew the picture, 'this is one of the pizzas, four out of four, it is a whole, and then we have a half of the pizza left— two out of four pieces left, ' and then another student is like 'sometimes we do not have enough room in the fridge so we layer them on each other." The layering action on a whole pizza is a nice visual of what the whole is-four-fourths in this case. Ms. Cordy adds, "The notion of what is the part what is the whole was so heavily reinforced... That was a big success that the denominator has to stay the same [when combining fractions with the same denominator]." In Ms. Cordy's excerpt she shared what she observed as the goal of a task - learning several concepts. She also shared the intent of her teaching-for students to understand. And she talked about big leaps made by some of her studentscombining fractions.

Several excerpts from the transcripts of the other two teachers also show instances that we characterize as learning through problem solving: For Ms. Sarina's class it was through the pendulum activity that "[the students] discovered on their own a mathematical concept ... the line of best fit." The students also appreciated why the line of best fit is used in graphs, "we use 
a line of best fit because there is a tendency." Further, "it is very hard to build a connection between them that these are all representations of the same thing. They saw it" Ms. Sarina also comments about the content explored: "You have to cover more than one [curriculum expectation in a good activity]."

Mr. Stocker focus on how students learn the language of a topic in the context of the problem: "the language starts to come out of the group when we are talking about the slope ... just quite naturally." "Sometimes you are adding in the language." Also, "there is this deepening complexity of the mathematical skills and it is all embedded in a context that has deep relevance to their ... lives."

Further all teachers appear to highlight that learning through problem solving is very helpful with content and skills that students usually find difficult. For instance, finding the points of intersection of two lines "is a very difficult skill and they [when working on the math of wage labor] can figure it out in many different ways (Mr. Stocker). They can figure it out physically... they can say ... well, let us extend our space here and go beyond five hours and see where we cross ... [It] is that - two lines crossing on the field." Finding the intersection of two lines on a graph is another "a very difficulty skill." He introduces scaffolding questions: So talk to me about the slope as we continue this way, so talk to me about what the y-intercept of 200 means in the real world. Can you go below the line? As students explore the Math of wage labor, Mr. Stocker observed, they also "begin to ask more complicated questions. Complicated concepts explored pendulum mathematics included the line of best fit as well as the connections among the different representations or a mathematics relationship. Unitizing, counting a group of objects as a unit, adding fractions and thinking about mixed number as fractions were the concepts successfully explored by Grade2/3 through problem solving. 


\section{A. Improving Teaching through Pedagogical Problem Solving}

The teachers' comments and reflections about their teaching practice help us see that their pedagogy is also developed by "improving their teaching through pedagogical problem solving." Several of the innovative teaching practices described by the teachers appear to emerge in the context of seeking to solve some common problems and tensions about mathematics teaching. For instance, Ms. Cordy differentiated the Chopsticks tasks into more than one option, borrowed a teaching strategy from another subject; Ms. Sarina used a physical experiments that involved electronic graphing; and Mr. Stocker integrated mathematics with social justice and incorporated kinesthetic experiences, all to address common tensions of diversity among learners, reduced curiosity, and hidden relevancy of the subject to students lives. What all three teachers shared were not pre-packaged or final solutions to what makes innovative or successful mathematics teaching but rather a work in progress or a problem whose solution they have worked on for some time and continue to refine.

Ms. Cordy's reflection on the spicy version of the Chopsticks task, for instance, best evinces that she continually seeks to improve her own teaching through problem solving: "I would do the problem again but now I am aware of the shortcomings." Another example of improving one's own teaching through solving a pedagogical problem is evidenced in what Ms. Cordy observed when she identified the source of misconception for the students who were arguing so passionately that six-fourth was not a fraction. The student "kept changing the whole ... So I went around ... I had to reinforce, so what is the whole? And what is the part?" Ms. Cordy also reflects on the advantages of using debates and other novel teaching approaches in mathematics teaching: "It is a bit of a risk that I took ... By taking this approach 
... it just stimulates the kids to talk and think and try prove it." From the fraction debate we see that Ms. Cordy is also attacking several pedagogical problems of lack of the affective component in learning mathematics, being stark in conventional ways of teaching mathematics and lack of contexts that make sense to learners. She remarks, "You have never seen 8 year olds so passionate about or so adamant that it [sixth-fourths] was not a fraction or that it was a fraction. And so bringing in that ... emotive part of it is really fun. I think about trying to borrow other great strategies from other areas not being stuck in what ought to be mathematics instruction." "We can take an opportunity to think about ... what makes sense." Mr. Stocker also addresses this problem of lack of emotional engagement among students when it comes to doing mathematics.

Pendulum mathematics for Ms. Sarina involved solving the following pedagogical problems: how do I make students curious about a mathematical concept? How do I make them engaged during an activity? How do I make what they learn easy to recall? "They leave this activity with questions and this is a better thing. "The knowledge that they acquire has to be answers to their questions." "And to create a situation where they have these kinds of questions ... What is this?" Mr. Stocker also addresses this problem of hidden relevance of mathematics to students' lives.

The wage labor problem for Mr. Stocker solves the following pedagogical problems: Why is it important to have math skills? The fortress of irrelevance is what Mr. Stocker refers to this problem as. He solves this problem by showing them that "in order to be a social justice advocate or activist it is really important to have solid mathematics skills.” By building mathematical activities around some of the questions [on the mathematics of wage labor] that they were interested in." "And most importantly for me particularly at [an alternative school with a focus 
on Social Justice issues] ... I think as an educator for me there has to be a real social context for the mathematics activities, in other words it has to make sense, it has to matter to the students' lives." The third pedagogical problem he notes is the lack of the kinesthetic component in mathematics lessons: When they graph the wage labor relations in the field, he observes that, "There is the kinesthetic component ... a lot of math activities stay too close to the mathematics intelligence and maybe the linguistic intelligence, but as soon as you move out in to the kinesthetic realm I think you engage a lot, a lot more of the students... I am looking for the opportunity to get out and move with your body because when you do things with your body it is much harder to forget." The other two teachers are also concerned about the pedagogical problem of reduced motivation, recall and meaning.

Just as students' learning went beyond specific isolated concepts to making connections among concepts, among representations and to real life, teachers learning went beyond content knowledge involved in the problems. They learned strategies that improve their own teaching practices. This parallel between learning mathematics through problem solving and learning to improve teaching through pedagogical problem solving was an unexpected connection when we started this project. It is also a connection that gives us hope about the future life and impact of the I Teach Math project. If this project helps teachers realize that learning, whether it is for students or for teachers, has this common element of through problem solving, then an important first step is taken to positively affect both students' learning and teachers' professional development. 


\section{BENEFITS AND FUTURE DEVELOPMENT}

Elsewhere [19] we share potential advantages of web based resources including sharing design features of innovative as well as teachers sharing their criteria of a successful teaching. This analysis of the ITM resources highlights that web based resources that share innovative teaching practices have the potential to show teachers' pedagogical thinking that guides and grows in practice. There are plans to update the I Teach Math web-resource to a live database, to which teachers are encouraged to annotate and add tasks. Websites work on and disseminate pedagogical content knowledge could be updated along the lines of: (a) offer tutorials; (b) encouraging teachers who access the database to create, annotate and add tasks to the pool; and (c) continually growing the databases by further developing and adding to the database exemplary tasks that teachers contribute (d) proving a forum in which to talk about connections among research, practice and affordances by digital technology.

\section{ACKNOWLEDGMENT}

We thank the teachers Michelle Cordy, David Stocker, and Vera Sarina that we interviewed for the I Teach Mathematics Project. 


\section{REFERENCES}

[1] D. L. Ball, "Knowing mathematics for teaching: Relations between research and practice. Mathematics and Education Reform Newsletter," 14 vol. 3, 1-5, 2002.

[2] B. Davis, and E. Simmt, "Complexity, cognition, and mathematics education research," Journal for Research in Mathematics Education, 34, vol. 2, 142-167, 2003.

[3] D. Clarke, M. Goos, and W. Morony, "Problem solving and working mathematically: An Australian perspective," ZDM Mathematics Education, 39, 475-490, 2007.

[4] S. Crespo and N. Sinclair, "What makes a problem mathematically interesting? Inviting prospective teachers to pose better problems," Journal of Mathematics Teacher Education, 11, 395-415, 2008.

[5] A. Ryve, "What is actually discussed in problem-posing courses for prospective teachers," Journal of Mathematics Teacher Education, 10, 43-61, 2007.

[6] D. Mewborn, "Teachers content knowledge, teacher education, and their effects on the preparation of elementary teachers in the United States" Mathematics Education Research Journal, 3, 28-36, 2001.

[7] Computers for Schools ,

[8] H. Ertl, and J. Plante, “Connectivity and Learning in Canada's Schools: Science, Innovation and Electronic Information Division,” Connectedness Series, 11. Statistics Canada, 2004.

[9] Ontario Ministry of Education, OME, Education Facts 2008-2009, 2009. Available at http://www.edu.gov.on.ca/eng/educationFacts.html.

[10] A. A. Brown, and H. Borko, H. (1992). "Becoming a mathematics teacher," in Handbook of Research on Mathematics Teaching and Learning, D. A. Grouws, Ed. New York: Macmillan, 1992, pp. 209-239. 
[11] I. K. Namukasa, G. Gadanidis, and M. Cordy, "How to feel about and learn mathematics: therapeutic intervention and attentiveness," Mathematics Teacher Education and Development, 9, 46-63, 2009.

[12] O. Chapman, "Classroom Practices for Context of Mathematics Word Problems," Educational Studies in Mathematics, 62(2), 211-30, 2006.

[13] NCTM, Principles and Standards for School Mathematics; Reston, VA: NCTM.

[14] Ontario Ministry of Education, OME, The Ontario Curriculum Grades 1-8: Mathematics, 2005. Toronto: Ontario Ministry of Education

[15] A. H. Schoenfeld, "Problem Solving in the United States, 1970-2008: Research and theory, practice and politics," ZDM Mathematics Education, 39, 537-551, 2007.

[16] G. Brousseau and P. Gibel, "Didactical Handling of students' reasoning processes in problem solving situations" Educational Studies in Mathematics, 59, 13-58, 2005.

[17] I. K. Namukasa, "Teaching through mathematics problems: Redesigned for a focus on mathematics," International Journal of Mathematics Trends and Technology, 1 vol. 1, 50-56, 2011.

[18] F. K. Lester, and R. L. Charles, Teaching mathematics through problem solving: Prekindergarten-Grade 6, Reston, VA: NCTM, 2003.

[19] I. K. Namukasa and G. Gadanidis, Databases for delivering pedagogical content knowledge for teaching mathematics: The I Teach Math example in Ontario, Canada. 3rd International Conference on Education and Computer, ICETC 2011, Changchun, China. ICETC proceedings, vol. 1, $227-232,2011$.

[20] J. Ellis, "Introduction: The teacher as interpretive inquirer," in Teaching From Understanding: Teacher As Interpretive Inquirer, J. L. Ellis, Ed. New York: Garland, pp. 
$5-13,1998$.

[21] S. Gallagher, Hermeneutics and education. Albany: State University of New York, 1992.

[22] A. Powell, J. Francisco and C. Maher, An analytical model for studying the development of learners' mathematical ideas and reasoning using videotape data. Journal of Mathematical Behavior, 22, vol. 4, 405-435, 2003.

[23] L. Martin, J. Towers, and S. Pirie, "Collective mathematical understanding as improvisation." Mathematical Thinking and Learning, 8 vol. 2, 149-183, 2006.

Immaculate K. Namukasa was born in Kampala, Uganda, Africa. She has a Doctoral degree in Education obtained at the University of Alberta, Edmonton, Alberta, 2004; and a bachelor of science in education and Masters in Science, Makerere University, 1995 and 2000 respectively. PhD, Msc., Bsc. This author became a Member (M) of IAENG in 2011. She currently is an Assistant Professor in mathematics education at the University of Western Ontario researching Dynamics of Attending in Mathematics Among Pre-service Teachers and Learners; Problem solving and its mathematical, experiential and pedagogical role; Theoretical discussions on use of virtual or concrete teaching materials; Curriculum reform in developing countries.

George Gadanidis is a professor at the University of Western Ontario, Her research interest in is in Math, Art and Technology. His work includes several funded projects and awards. A selected list of his publications may be found at http://publish.edu.uwo.ca/george.gadanidis/ . This author became a Member (M) of IAENG in 2011. 